\title{
The Method for Improving the Undergraduate Ability of Electrical Specialty under the New Background of Power Industry Development
}

\author{
Xiao-fang MENG ${ }^{1}$, Li-di WANG ${ }^{1,{ }^{*}}$ and Ying-nan WANG ${ }^{2}$ \\ ${ }^{1}$ The College of Information and Electric Engineering, Shenyang Agricultural University, Shenyang \\ 110866, China; \\ ${ }^{2}$ Shenyang Association for Science and Technology, Shenyang 110063, China \\ ${ }^{*}$ Corresponding author
}

Keywords: Electrical specialty, Graduation design, Power industry, Undergraduate ability.

\begin{abstract}
In order to improve the undergraduate ability of electrical specialty, this paper studies the way of training undergraduate ability by means of graduation design. In the logic order of raising problems, analyzing problems and solving problems, based on the necessary survey and broad references, the undergraduate of electrical specialty was guided to determine the research direction, put forward questions, and determine the title of the graduation design. By enlightening method to clear the relevant concepts on references, undergraduate ability of overall view was developed to analyze problem, determine the specific content and methods of the research problems, and formulate specific implementation steps. Finally, the ability to solve the problem was trained, and undergraduate was guided to set up the specific system figure and mathematical model, and complete the related calculation and result analysis. The method proposed in this paper was illustrated in detail with the example of "load forecasting method of distribution network considering the influence of wind power generation". Graduation design practices show that the method proposed in this paper can obviously improve the comprehensive ability of the undergraduates of electrical specialty.
\end{abstract}

\section{Introduction}

In recent years, great changes have taken place in power system. The distributed generation (DG) are developed rapidly, the microgrids has been created and promoted by DGs, and the race to build smart grid is on [1]. With rapid development wind power, solar power, hydropower and other renewable energy, the transformation of energy production to renewable energy is a major demand for sustainable development of energy and economy in China and the whole world [2].Under this new development background, the power industry needs a large number of excellent talents, especially the undergraduates with certain skills. With the development of the power industry, it is urgent to improve the undergraduate ability and reserve talents for the power industry. In the teaching system of cultivating electrical undergraduate ability, it includes basic theory, professional theory, curriculum design, graduation design, experiment and practice, etc. The graduation design plays an irreplaceable role for undergraduate of electrical Specialty. It is not only the basic training for the integration of undergraduates' knowledge, but also the basic method for cultivating student creative thinking in the teaching system [3].

In order to enhance the undergraduate ability of electrical specialty based on the undergraduate graduation design and the development of power industry, this paper aims at training undergraduates' ability of asking questions, analyzing problems and solving problems, and studies the methods to enhance undergraduate ability in electrical majors. 


\section{The Method of Improving the Undergraduate Ability}

\section{Cultivation the Undergraduate Ability of Posing Questions}

The ability of posing questions is the key to cultivating the creative ability of undergraduate. With the rapid development of power industry, the content of power industry is more and more extensive, such as power network planning, distributed generation optimization and control, load forecasting, smart grid, and so on[4-7]. For an undergraduate, it is not easy to put forward a specific problem. It is necessary to guide the students to do the necessary research, and read a certain amount of references. Then it is possible to determine a certain direction of research. After determining the direction of research, undergraduate can confirm the research status and trend of the research direction on the related literature, so that undergraduate can be guided to ask questions and clarify their goals. Next, undergraduate can confirm the title of graduation design.

\section{Cultivation the Undergraduate Ability of Analyzing Problems}

The cultivation of the ability of analyzing problems begins with to read the literature purposefully and define the relevant concepts. Then, from the overall view, the ability to analyze problem is trained. Undergraduate should be guided to have a comprehensive understanding of the problems studied, roughly outline the framework of implementation, identify the specific contents of the research questions, formulate specific implementation steps, and determine the methods used.

Further, the first level headings in the directory should be determined. The completion sequence of each chapter needs to be formulated and the time used is estimated. Then the undergraduate can analyze the contents of each chapter and contact between each other, and determine the second, third, and following level headlines of each chapter. The next step is to guide the students to analyze how the chapters are organized, to determine the basic contents of the chapters and the focus of the study. For the focus of research, students need to further study and analyze.

\section{Cultivation the Undergraduate Ability of Solving Problems}

After careful analysis of graduation design title, the undergraduate can be guided to solve problems concretely, establish specific system diagrams and mathematical models, confirm specific steps, and complete load forecasting. In this process, undergraduate' knowledge will be integrated, such as mathematics, computer technology, advanced programming language, basic courses, specialized courses, foreign languages, etc.

\section{Example of Graduation Design}

\section{Preliminary Analysis Process}

An undergraduate graduated in 2016 is taken as an example to illustrate the above method. The undergraduate took a month to determine the title of the graduation design, "load forecasting method of distribution network considering the influence of wind power generation". The primary task is to clarify related concepts, such as content of load forecasting [4], significance of load forecasting [8], influence factors of load forecasting $[6,9,10]$, characteristics of grid-connected wind power [5], the accuracy significance of load forecasting [2], etc. The second task is to study methods of load forecasting [4, 11]. Because the grey prediction method can comprehensively reflect many factors [4], and explore the inherent rule of raw data based on data mining and processing [12], the undergraduate finally uses grey prediction to predict the load with wind power.

\section{Simple System of Grid-connected Wind Power}

The simple system of grid-connected wind power generation is shown in Figure 1. 


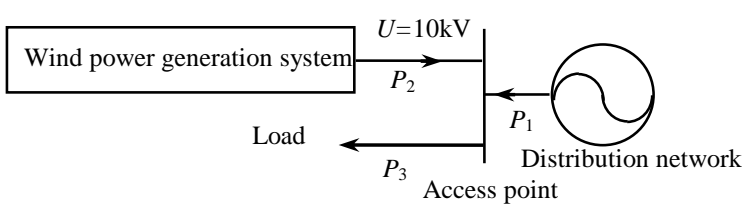

Figure 1. Simple system of grid-connected wind power

At the access point in Figure 1, the relationship of active power is as follows:

$$
P_{3}=P_{2}+P_{1}
$$

Where, $P_{1}$ is the active power from the distribution network (MW); $P_{2}$ is the active power from wind power generation (MW); $P_{3}$ is the active power consumed by the user (MW).

\section{Development of GM $(1, n)$ Model}

In order to predict the $P_{1}$, the GM $(1, n)$ model was established by the grey prediction method [13]. Assuming that there are $n$ variables: $x_{1}, x_{2}, \ldots, x_{n}$, original series formed by these variables are as follows:

$$
\boldsymbol{x}_{i}^{(0)}=\left[x_{i}^{(0)}(1), x_{i}^{(0)}(2), \ldots, x_{i}^{(0)}(n)\right](i=1,2, \ldots, n)
$$

The randomness of the original data $\boldsymbol{x}_{i}^{(0)}$ is weakened, and a new series $\boldsymbol{x}_{i}^{(1)}$ is generated, which is:

$$
\begin{aligned}
\boldsymbol{x}_{i}^{(1)} & =\left[x_{i}^{(1)}(1), x_{i}^{(1)}(2), \ldots, x_{i}^{(1)}(n)\right] \\
& =\left[\sum_{m=1}^{1} x_{i}^{(0)}(m), \sum_{m=1}^{2} x_{i}^{(0)}(m), \ldots, \sum_{m=1}^{n} x_{i}^{(0)}(m)\right](i=\mathbf{1}, 2, \ldots, n)
\end{aligned}
$$

The GM $(1, n)$ model is constructed, the first order linear differential equation of $n$ variable, is as follows:

$$
\frac{d x_{1}^{(1)}}{d t}+a x_{1}^{(1)}=b_{1} x_{2}^{(1)}+b_{2} x_{3}^{(1)}+\ldots+b_{n-1} x_{n}^{(1)}
$$

The parameter $\hat{\boldsymbol{a}}$ of the above equation is listed as:

$$
\hat{\boldsymbol{a}}=\left(a, b_{1}, b_{2}, \cdots, b_{n-1}\right)^{\mathrm{T}}
$$

The parameter $\hat{\boldsymbol{a}}$ is solved by the following formula:

$$
\begin{aligned}
\hat{\boldsymbol{a}} & =\left(\boldsymbol{B}^{\mathrm{T}} \boldsymbol{B}\right)^{-1} \boldsymbol{B}^{\mathrm{T}} \boldsymbol{Y}_{\boldsymbol{n}} \\
\boldsymbol{B} & =\left[\begin{array}{cccc}
-\frac{1}{2}\left[x_{1}^{(1)}(1)+x_{1}^{(1)}(2)\right] & x_{2}^{(1)}(2) & \ldots & x_{n}^{(1)}(2) \\
-\frac{1}{2}\left[x_{1}^{(1)}(2)+x_{1}^{(1)}(3)\right] & x_{2}^{(1)}(3) & \ldots & x_{n}^{(1)}(3) \\
\ldots & & & \\
-\frac{1}{2}\left[x_{1}^{(1)}(n-1)+x_{1}^{(1)}(n)\right] & x_{2}^{(1)}(n) & \ldots & x_{n}^{(1)}(n)
\end{array}\right] \\
\boldsymbol{Y}_{n} & =\left[\begin{array}{c}
x_{1}^{(0)}(2) \\
x_{1}^{(0)}(3) \\
\ldots \\
x_{1}^{(0)}(n)
\end{array}\right]
\end{aligned}
$$

After obtaining the unique solution of the parameter $\hat{\boldsymbol{a}}$, the prediction equation of $n$ variables is obtained, as follows: 


$$
\hat{x_{1}^{(1)}}(k+1)=\left[x_{1}^{(0)}(1)-\frac{1}{a} \sum_{i=2}^{n} b_{i-1} x_{i}^{1}(k+1)\right] e^{-a k}+\frac{1}{a} \sum_{i=2}^{n} b_{i-1} x_{i}^{1}(k+1)
$$

The prediction model of $x_{1}^{(0)}$ can be obtained by the reduction subtraction calculation, as follows:

$$
\hat{x_{1}^{(0)}}(k+1)=\hat{x_{1}^{(1)}}(k+1)-\hat{x_{1}^{(1)}}(k)
$$

\section{Load Forecasting Based on Grey Prediction Model}

Considering the influence of wind power generation $P_{2}$, the GM $(1, n)$ model is used to predict the of distribution network power $P_{1}$ in Figure 1 . The $P_{1}$ is the original series $x_{1}^{(0)}$, and the original number of the $P_{2}$ is the original series $x_{2}^{(0)}$, and the specific data of is $x_{1}^{(0)}$ and $x_{2}^{(0)}$ shown in Table 1 .

Table 1. Historical data on power distribution and wind power

\begin{tabular}{|c|c|c|c|c|c|}
\hline Number & 1 & 2 & 3 & 4 & 5 \\
\hline Date & May 10th & May 11th & May 12th & May 13th & May 14th \\
\hline$x_{1}^{(0)}(k)[\mathrm{MW}]$ & 5.36 & 5.49 & 5.35 & 5.65 & 5.27 \\
\hline$x_{2}^{(0)}(k)[\mathrm{MW}]$ & 0.14 & 0.15 & 0.13 & 0.16 & 0.14 \\
\hline
\end{tabular}

Using formula (2)-(10), the parameters $a$ and $b$ have been calculated, $a=2.005, b=75.736$. The following differential equation has been listed as follows:

$$
\frac{d x_{1}^{(1)}}{d t}+2.005 x_{1}^{(1)}=75.736 x_{2}^{(1)}
$$

The prediction equation established by the formula (9) is as follows:

$$
\hat{x_{1}^{(1)}}(k+1)=\left[5.36-37.78 x_{2}^{(1)}(k+1)\right] e^{-2.005 k}+37.78 x_{2}^{(1)}(k+1)
$$

The prediction model of $x_{1}^{(1)}$ has been tested. The predictive value $x_{1}^{(0)}$ by the formula (10) has been calculated, as shown in Figure 2. And the reduction test has been completed, as shown in Figure 3.

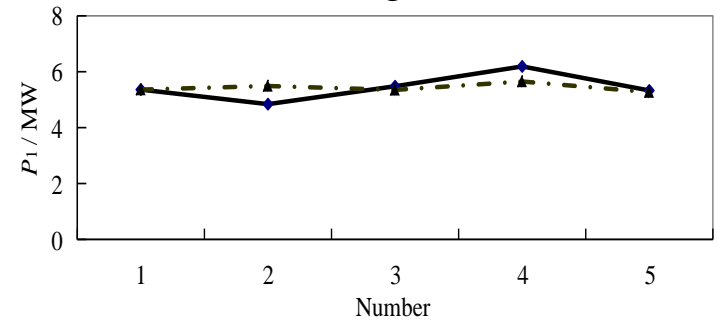

Figure 2. Prediction curve of distribution network power $P_{1}$

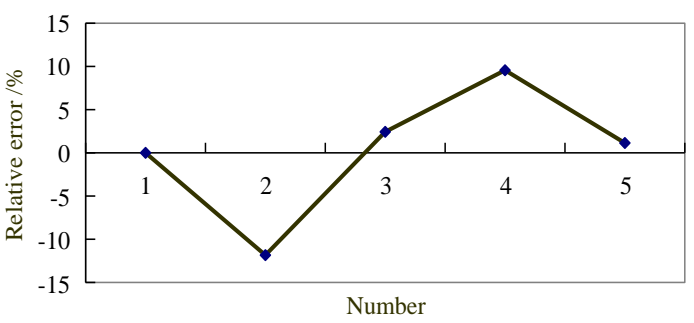

Figure 3. Relative error curve

In Figure 2, the solid line is a prediction curve, and the dotted line is the actual power curve. Compared with the actual power value, the reduction test is completed, and the relative error curve is shown in Figure 3. The average relative error is $0.258 \%$, and the maximum relative error is $-11.84 \%$. Using the grey prediction model, the distribution network power $P_{1}$ has been predicted on May 15, 2015, and the specific value is as follows:

$$
\hat{x_{1}^{(0)}}(6)=\hat{x_{1}^{(1)}}(6)-\hat{x_{1}^{(1)}}(5)=32.11-27.20=4.91 \mathrm{MW}
$$

The actual power $x_{1}^{(0)}(6)$ is $5.04 \mathrm{MW}$ on May 15, 2015. The relative error between the forecast value and the actual value is $2.58 \%$.

\section{Conclusion}

With the rapid development of the power industry, a large number of outstanding undergraduates of electrical specialty are needed, and the undergraduate ability is becoming more and more important. 
The graduation design can be used to integrate electrical specialty students' knowledge together. In the graduation design, the undergraduates can be guided to establish corresponding mathematical models, compile corresponding programs or establish simulation models, solve problems and analyze the results. Therefore, undergraduates are trained to raise questions, analyze and solve problems, and to further cultivate the creative thinking of undergraduate. It is important that the creative thinking of undergraduates has been trained.

\section{Acknowledgement}

This work was financially supported by the national science and technology support branch project (2012BAJ26B00), the natural science foundation of Liaoning Province (2014027001), and the educational science planning project of Liaoning Province (JG16DB388).

\section{References}

[1] Xiaofang Meng, Yingnan Wang, Lisi Fu, and et al, Improve the Graduate's Practice Ability of Electrical Specialty by the Graduation Design, 2014 International Conference on Advanced Education and Management (2014).

[2] Chongqing Kang, Liangzhong Yao, Key Scientific Issues and Theoretical Research Framework for Power Systems with High Proportion of Renewable Energy, Automation of Electric Power Systems. 9 (2017) 2-11.

[3] Xiaofang Meng, Zailin Piao, Youwen Tian, Research on coping strategy to improve the Graduation Design quality of the Electrical Specialty, China Electic Power Education. 27 (2011) 130-131.

[4] Zailin Piao, Xiaofang Meng, Distribution network planning, First ed., Electric Power Press, Beijing, China, 2015.

[5] Wanxing Sheng, Keyan Liu, Sheng Cheng, Optimal power flow algorithm and analysis in distribution system considering distributed generation, IET Generation, Transmission \& Distribution., 2 (2014) 261-272.

[6] VASILAKOS A, HU J, Energy big data analytics and security: challenges and opportunities, IEEE Trans on Smart Grid. 5 (2016) 2423-2436.

[7] Shuzuo Wei, Bin Cai, Relations Between Rapid Development of Power Grids in China and Power Generation by Renewable Energy Resources, Power System Technology. 5 (2008) 26-30.

[8] Chongqing Kang, Qing Xia, Mei Liu, Power system load forecasting, First ed., Electric Power Press, Beijing, China, 2007.

[9] Hadi Z, Azah, Hussain S.Marjan, Impact of Distributed Generations on Power System Protection Performance, International Journal of the Physical Science. 16 (2011) 3873-3881.

[10] Xiaofang Meng,ShuXuan Zhang, Jun Wang, et al, Load forecasting method considering temperature effect for distribution network, 2016 International Conference on Electronic, Control and Computer Engineering (2016).

[11] Wen Jinbin, Wang Xin, Li Lixue, et al. Short-Term Wind Power Load Forecasting Based on Frequency Domain Decomposition. Transactions of China Electrotechnical Society, 5 (2013) 66-72.

[12] Keyi Zhang. STOCK PRICE PREDICTING BASED ON THE COMPOSITE MODEL OF IMPROVED GM (1,N) AND OPTIMIZED SVM. Harbin Institute of Technology, 6 (2013) 3,23-24

[13] Zhou Ye, Kangmin Chen, Integrated forecasting of $\operatorname{GM}(1,1)$ and $\operatorname{GM}(1, N)$ based on self-correlation theory, J. University of Shanghai for Science and Technology, 1 (2002) 17-20. 